This is the author's final, peer-reviewed manuscript as accepted for publication. The publisher-formatted version may be available through the publisher's web site or your institution's library.

\title{
Size focusing of nanoparticles by thermodynamic control through ligand interactions. Molecular clusters compared with nanoparticles of metals
}

Deepa Jose, John E. Matthiesen, Christopher Parsons, Christopher M. Sorensen, and Kenneth J. Klabunde

\section{How to cite this manuscript}

If you make reference to this version of the manuscript, use the following information:

Jose, D., Matthiesen, J. E., Parsons, C., Sorensen, C. M., \& Klabunde, K. J. (2012). Size focusing of nanoparticles by thermodynamic control through ligand interactions: Molecular clusters compared with nanoparticles of metals. Retrieved from http://krex.ksu.edu

\section{Published Version Information}

Citation: Jose, D., Matthiesen, J. E., Parsons, C., Sorensen, C. M., \& Klabunde, K. J. (2012). Size focusing of nanoparticles by thermodynamic control through ligand interactions: Molecular clusters compared with nanoparticles of metals. Journal of Physical Chemistry Letters, 3(7), 885-890.

Copyright: (c) 2012 American Chemical Society

Digital Object Identifier (DOI): doi:10.1021/jz201640e

Publisher's Link: http://pubs.acs.org/doi/abs/10.1021/jz201640e

This item was retrieved from the K-State Research Exchange (K-REx), the institutional repository of Kansas State University. K-REx is available at http://krex.ksu.edu 
Size Focusing of Nanoparticles by Thermodynamic Control through Ligand Interactions.

Molecular Clusters Compared with Nanoparticles of Metals

Deepa Jose,${ }^{\dagger}$ John E. Matthiesen, ${ }^{\dagger,}{ }^{\dagger}$ Christopher Parsons, ${ }^{\dagger, \S}$ Christopher M. Sorensen, ${ }^{1}$ and Kenneth J. Klabunde ${ }^{* \dagger}$

${ }^{\dagger}$ Department of Chemistry and ${ }^{\mathrm{t} D e p a r t m e n t}$ of Physics, Kansas State University, Manhattan, Kansas 66506, United States

${ }^{\star}$ Wartburg College, Waverly, Iowa 50677, United States

${ }^{\S}$ Department of Chemistry, University of Georgia, Athens, Georgia 30602, United States

Phone: 785-532-6849

e-mail:kenjk@ksu.edu

Fax: 785-532-6666 


\begin{abstract}
Ligand capped metal entities come in two sizes; (1) molecular clusters of $10-200$ metal atoms, and (2) nanoparticles of 2000 - 10000 metal atoms. In numerous cases, certain "magic sizes" have been found to be most accessible and stable; clusters of 25, 38, 55, 102 atoms and nanoparticles of $3500-5000$ atoms or $4-5 \mathrm{~nm}$. The most familiar and studied system is that of gold (metal) and thiol (ligand). Herein the methods of synthesis of these gold clusters vs gold nanoparticles are carefully compared. In the cluster case, an important intermediate is $\left(\mathrm{Au}^{+}-\mathrm{SR}\right)_{\mathrm{n}}$ polymer, which is not the case in the synthesis of nanoparticles either from metal (vapor) atoms or metal ions. Also, it is shown that thiol can act as both a reductant $\left(\mathrm{Au}^{3+} \longrightarrow \mathrm{Au}^{1+}\right)$, and as an oxidant $\left(\mathrm{Au}^{0} \longrightarrow \mathrm{Au}^{1+}\right)$. The thermodynamic forces responsible for the favored formation of certain size clusters, and nanoparticles are discussed.
\end{abstract}

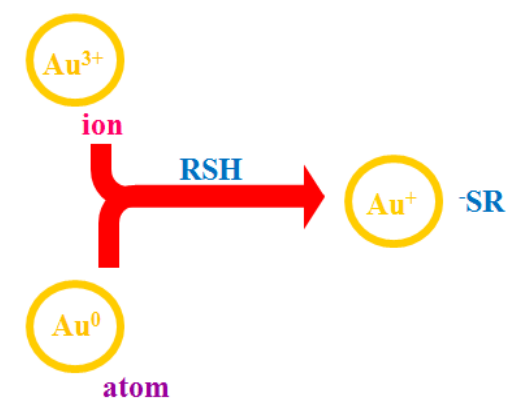

Thiol reduces gold(III) ion to gold(I), and oxidized gold atoms to gold(I). 


\section{Introduction}

In what has become a large and vigorous research area, that of ligand capped metal nanoparticles, a tendency toward certain sizes has been observed by many workers. ${ }^{1-12}$ Gold has been studied most extensively, and it has been interesting to observe that the results can be separated into two categories: (1) small nanocrystals, better termed clusters of gold atoms, such as $\mathrm{Au}_{24},{ }^{13} \mathrm{Au}_{25},{ }^{14-18} \mathrm{Au}_{38},{ }^{11,19} \mathrm{Au}_{102},{ }^{20} \mathrm{Au}_{130},{ }^{21} \mathrm{Au}_{144},{ }^{22} \mathrm{Au}_{225},{ }^{23}$ and a few others; (2) gold nanoparticles of $3-5 \mathrm{~nm}$ (1000 to 4000 atoms $)^{1-5}$ and sometimes $9-10 \mathrm{~nm}^{24}$ For both categories it has been shown that there are clearly numerous examples of size focusing under apparent thermodynamic control. In the case of the "larger" particles this has been called digestive ripening, although with the clusters it has been called "size focusing".

A fair question is "what features of the synthetic methods employed caused this thermodynamic control"? Also, "why are these vastly different sizes obtained?" The ligands employed are certainly important. For example, excess dodecylthiol with gold nanoparticles under reflux in toluene led to monodisperse $4.5 \pm 0.4 \mathrm{~nm}$ particles, ${ }^{4}$ and variation in alkyl chain length led to only minor changes in the sizes achieved. ${ }^{25}$ On the other hand, dodecylamine led to narrow size distribution with $8.6 \pm 1.3 \mathrm{~nm}$ size. ${ }^{24}$ Interstingly, these results were found with two quite different synthetic approaches; metal vapor derived nanoparticles ${ }^{4}$ where only zero-valent particles were present, and inverse micelle stabilized gold ions reduced by sodium borohydride eventually leading to zero-valent particles. ${ }^{26}$ It should be noted that the digestive ripening step was carried out in refluxing organic solvents, usually toluene. When a similar approach was carried out in water, using water soluble thiol ligands, digestive ripening still occurred, but the resultant nanoparticles were slightly smaller $(4.2 \pm 0.5 \mathrm{~nm}){ }^{27}$ 
For the gold cluster work the synthetic approaches are quite different and usually include a two step reduction of $\mathrm{Au}(\mathrm{III})$ with polymeric $\mathrm{Au}(\mathrm{I})$-SR formed as an intermediate. ${ }^{15}$ Also, the thiols studied in the gold thiol work were of different structures. The most commonly used was 2-phenylethanethiol $\left[\mathrm{C}_{6} \mathrm{H}_{5} \mathrm{CH}_{2} \mathrm{CH}_{2} \mathrm{SH}\right]$ or water soluble thiols such as glutathione. ${ }^{10}$ In comparison, in the nanoparticles work, usually long chained alkyl thiols were employed such as straight chained dodecylthiol $\left[\mathrm{C}_{12} \mathrm{H}_{25} \mathrm{SH}\right]$.

A comparative study was needed, which will be discussed now.

\section{A. Solvated Metal Atom Dispersion (SMAD)}

The metal vapor method employed the Solvated Metal Atom Dispersion (SMAD) process. ${ }^{4}$ Metal vapor (atoms) are trapped in frozen solvent at $77 \mathrm{~K}$, and upon warming the atoms migrate to find other atoms, and nanoparticles are thus formed. Ultimate size depends on the solvent employed, amount used, and polarity. Solvents such as acetone, butanone, or tetrahydrofuran (THF) allow stable colloids to form with gold, which are red in color, show an absorption in the UV-vis representative of a plasmon resonance $(520 \mathrm{~nm})$, and by TEM bright field imaging $2-8$ $\mathrm{nm}$ in size when butanone was used as a solvent (see scheme 1 and Figure 1a).

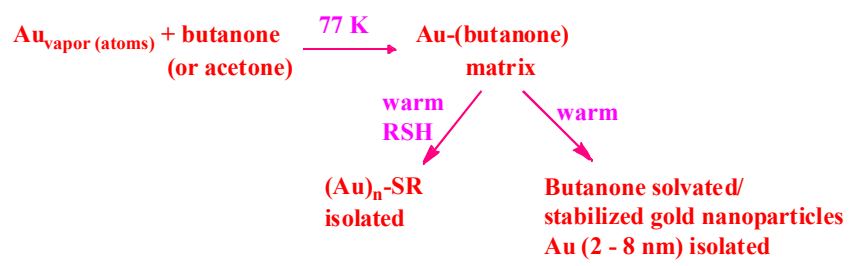

Scheme 1 Metal vapor method (SMAD) for preparing nanoparticles of gold in a weakly coordinating solvent, followed by treatment with thiols. 


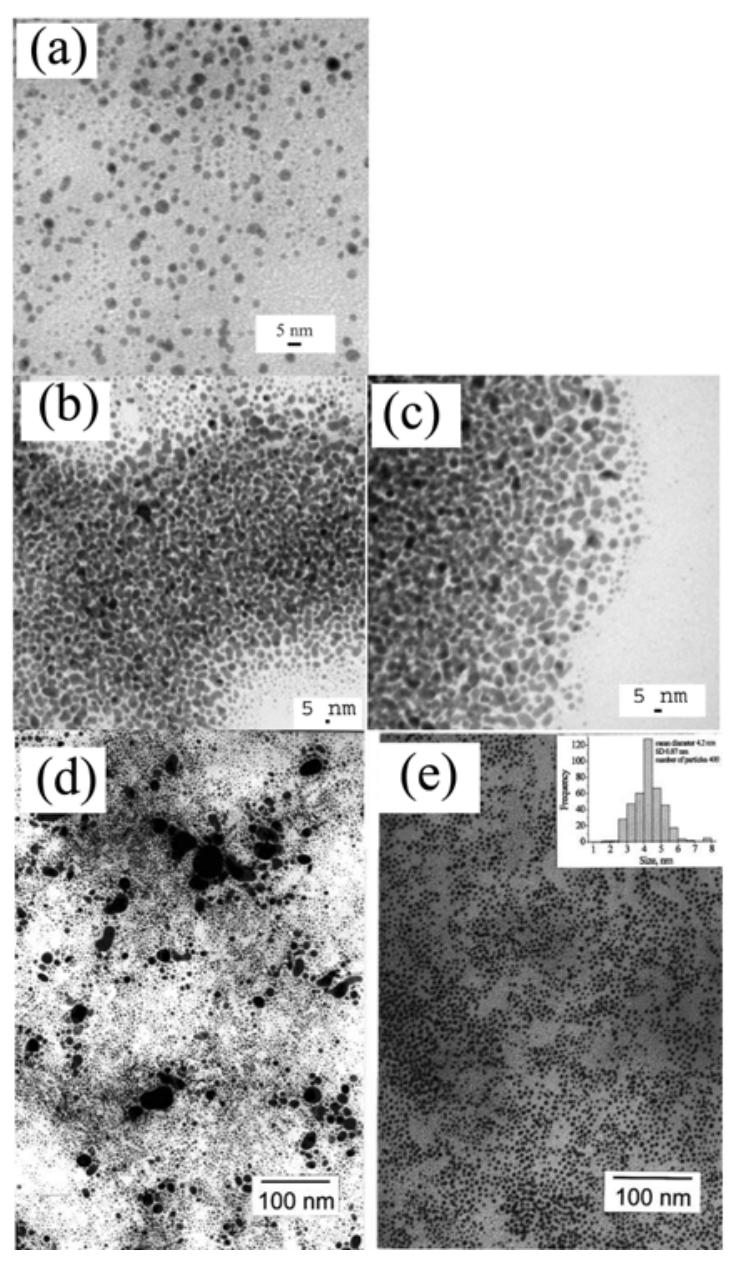

Figure 1 TEM images of SMAD (a) Isolated Gold-butanone colloid and (b) Gold-2phenylethanethiol immediately after isolation; (c) after digestive ripening in toluene; (d) Golddodecylthiol immediately after isolation; (e) after digestive ripening

When the gold-butanone cold matrix was allowed to melt down and mix with a thiol ligand, immediately the weakly solvating butanone was replaced by R-SH. Two thiols were compared: dodecylthiol (DDT) and 2-phenylethanethiol (PET). The colloids formed were brown (DDT) and yellow-brown (PET). Both exhibited featureless UV-vis spectra with decreasing absorption with increasing wavelength. However, the two thiols did behave differently over time, the DDT colloid being very stable while the PET colloid was not and a precipitate formed that 
resisted redissolution. This precipitate was probably a $\mathrm{Au}(\mathrm{I})$-thiolate polymer (see later discussion).

\section{Digestive ripening}

A direct comparison of DDT and PET in toluene solvent was carried out. In these experiments DDT or PET was placed in the bottom of the reactor, vacuum and liquid nitrogen

cooling was applied, and toluene vapor was deposited on the reactor walls. Then, the cooling dewar was removed and toluene allowed to melt and mix with the DDT (or PET). Then cooling was again applied, and the vapors of acetone (or butanone) were co-deposited with gold vapor. Upon completion, the acetone-gold matrix was allowed to melt and atom accretion began as the melt moved down and mixed with the toluene-DDT (or PET) solution.

(1) Au-acetone-toluene-dodecanethiol colloid ${ }^{4}$

The as-prepared Au-acetone-toluene-dodecanethiol colloid was dark brown in color with particles of no definite geometrical shapes and size varying from 5 to $40 \mathrm{~nm}$. The UV-visible spectrum of the as-prepared sample was very broad, which is consistent with the TEM results. The digestive ripening of the as-prepared dodecanethiol capped gold colloid in toluene after removal of the initial weak capping agent, acetone, gave great improvement in the particle size distribution. The average particle diameter was found to be $4.5 \pm 0.4 \mathrm{~nm}$ after digestive ripening for $1.5 \mathrm{~h}$. Also the UV-visible spectrum of the digestively ripened sample became narrow with an absorption maximum around $513 \mathrm{~nm}$ (see Figure 1). ${ }^{4}$

(2) Au-acetone-toluene-2-phenylethanethiol colloid

The as-prepared Au-acetone-toluene-2-phenylethanethiol colloid was brownish red in color and the UV-visible spectrum showed a shoulder around $500 \mathrm{~nm}$. The TEM bright field images of the as-prepared sample showed a mixture of particles: isolated spherical particles of 
size varying from 2 to $40 \mathrm{~nm}$ and necked particles of no definite geometry. The digestive ripening of the as-prepared sample for $1.5 \mathrm{~h}$ in toluene after the removal of acetone did not show any change in the color (brownish red). The UV-visible spectrum did not change. The TEM bright field image of the digestively ripened sample showed network of necked particles along with a few isolated spherical particles (see Figure 1).

\section{B. Inverse Micelle Method ${ }^{28}$}

To repeat, the main interest was in comparing DDT and PET. In the inverse micelle method, gold salts are reduced in the presence of a surfactant in an organic solvent containing small amounts of water. ${ }^{28}$ Usually the reducing agent is $\mathrm{NaBH}_{4}$. When didodecyldimethylammonium bromide (DDAB) was used as the surfactant and $\mathrm{NaBH}_{4}$ as a reducing agent, upon addition of DDT the orange solution turned purple-red immediately. However, when PET was added a dark blue color resulted. When the colloidal gold particles were isolated by precipitation with ethanol, washed, and dried, the DDT particles were readily soluble in toluene. However, the PET particles were quite insoluble and only by using sonication could they be resuspended. TEM studies (Figure 2a) showed in the case of PET, agglomerated masses of very small particles. Similar results were observed when THF was used as solvent in place of toluene. Thus, to summarize, nanoparticles formed with DDT followed by digestive ripening, always yielded spherical quasi-monodisperse particles in the $5 \mathrm{~nm}$ size range $(4.6-5.5 \mathrm{~nm})$. This was true even with comparing several preparations and even different solvents (toluene or THF). However, digestive ripening using PET led to a network of small particles, more polymeric in nature (Figure 2b).

At this point, it is useful to describe the differences between DDT and PET under the same experimental conditions: In the case of DDT the tendency is toward growing $5 \mathrm{~nm}$ gold 
particles and these are honed to near monodispersity by digestive ripening. However, in the case of PET, the gold particles formed by the SMAD method or the Inverse Micelle method, tend toward very small particles that strongly aggregate. That is, under both experimental conditions, SMAD and inverse micelle, when PET is used, the product formed is aggregated networks of necked particles. Moreover, an $\mathrm{Au}(\mathrm{I})$-thiolate polymer was formed from the as-prepared $\mathrm{Au}-$ butanone-PET SMAD colloid after storing under argon for several days.
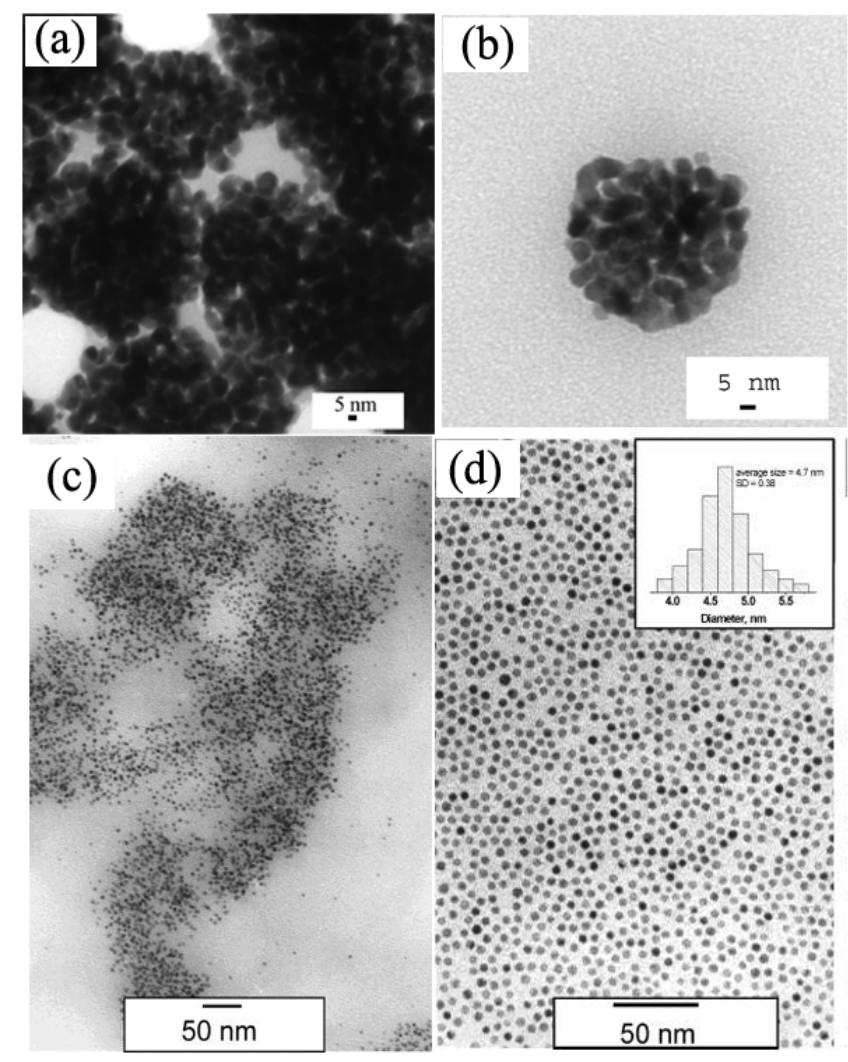

Figure 2 Inverse Micelle TEM bright field images of Au-PET and Au-DDT colloids (a) PET before digestive ripening, (b) PET after digestive ripening, (c) DDT before digestive ripening, and (d) DDT after digestive ripening

In the introduction the two categories of gold nanoparticle research were brought up; (1) very small nanoparticles where Au clusters of 25, 38, 105, 225 atoms and others have been 
isolated as thiolate complexes, either neutral or negatively charged overall, and (2) the large class of gold-thiolate particles are formed where $5 \mathrm{~nm}$ particles, or usually about $\mathrm{Au}_{3800}(\mathrm{SR})_{365}$. In the latter case, the $5 \mathrm{~nm}$ particles, since no X-ray crystal structures have been possible to obtain, the evidence for thiolate $\left[\mathrm{RS}^{-}\right]$vs $\mathrm{RSH}$ as the capping ligand has not been as clear. ${ }^{29}$ However, based on the recent evidence of Creutz and co-workers, ${ }^{30}$ when surfactant stabilized gold nanoparticles were allowed to react with thiols, a substantial portion, though not quantitative, of hydrogen gas was released. Inspired by the Creutz work and by years of uncertainty of what actually happens to the hydrogen in gold-thiol reactions, a series of SMAD experiments were carried out. Here, weakly solvated gold nanoparticles (acetone solvent) were allowed to contact dodecylthiol, and hydrogen gas was evolved. Control experiments with pure acetone, did not show hydrogen gas evolution. ${ }^{31}$

In the case of DDT, the amount of hydrogen evolved was $15 \mu \mathrm{mol}$ while $230 \mu \mathrm{mol}$ of gold was used, while in the case of PET $31 \mu \mathrm{mol} \mathrm{H}_{2}$ and $456 \mu \mathrm{mol}$ gold. In another set of experiments the isolated, purified gold-thiol nanoparticles were analyzed by Thermo Gravimetric Analysis (TGA) by heating in air, the thiol/thiolate was oxidized away leaving only gold. Results: DDT $0.75 \mu \mathrm{mol}$ thiolate vs $6.2 \mu \mathrm{mol}$ gold; PET $3.2 \mu \mathrm{mol}$ thiolate vs $25 \mu \mathrm{mol}$ gold.

$$
\begin{aligned}
& \mathrm{Au}_{\mathrm{x}}+\mathrm{HSR} \longrightarrow \mathrm{Au}_{\mathrm{n}}(\mathrm{SR})_{\mathrm{m}}+1 / 2 \mathrm{H}_{2} \\
& \mathrm{Au}_{\mathrm{n}}(\mathrm{SR})_{\mathrm{m}} \stackrel{\text { heat }}{\longrightarrow} \mathrm{nAu}+\text { gases }\left(\mathrm{SO}_{2}, \mathrm{CO}_{2}, \mathrm{H}_{2} \mathrm{O}\right)
\end{aligned}
$$

Comparing these experimental approaches indicated that the moles of hydrogen gas produced were about equal to the moles of thiolate produced within $7 \%$. These data also indicated that there are eight times as many atoms of gold as thiolate molecules; by $\mathrm{H}_{2}$ production $\mathrm{Au} / \mathrm{H}=7.6$, and by $\mathrm{TGA} A u / \mathrm{SR}=8.2$. The same experiments with PET yielded essentially the same results with respect to hydrogen/gold and thiolate/gold. The ratios of $\mathrm{Au} / \mathrm{H}=$ 
7.4 and $\mathrm{Au} / \mathrm{SR}=7.7$. It can be concluded that at room temperature both DDT and PET react with weakly solvated gold nanoparticles to form gold-thiolate structures plus hydrogen gas.

The TEM results show that SMAD gold-acetone or gold-butanone colloids before the addition of the thiols, range from $2-8 \mathrm{~nm}$. These $\mathrm{Au} / \mathrm{SR}$ ratios can be used to estimate the gold nanoparticles size. We assume spherical particles of gold with the bulk density of $19.34 \mathrm{~g} / \mathrm{cc}$. We take the thiol to occupy a surface area of $0.215 \mathrm{~nm}^{2}{ }^{2}$. Then one can show that the total number of gold atoms in the nanoparticle, $\mathrm{N}(\mathrm{Au})$, and the total number of thiol ligands on the surface of the nanoparticles, $\mathrm{N}(\mathrm{SR})$, are given by: $\mathrm{N}(\mathrm{Au})=31 \mathrm{~d}^{3}$ and $\mathrm{N}(\mathrm{SR})=14.67 \mathrm{~d}^{2}$, where $\mathrm{d}=$ particle diameter in nanometers. The $\mathrm{Au} / \mathrm{SR}$ ratio is identically equal to $\mathrm{N}(\mathrm{Au}) / \mathrm{N}(\mathrm{SR})$. Then with the above equation one finds $\mathrm{d}=0.47 \mathrm{Au} / \mathrm{SR}$. Above we found $\mathrm{Au} / \mathrm{SR} \approx 8$ to imply, by the above equation, $\mathrm{d} \approx 4 \mathrm{~nm}$. This is quite consistent with TEM observation of the particles which show the sizes ranging from 2 to $8 \mathrm{~nm}$.

The main conclusion, however, is that these experiments yield gold-thiolate structures, not gold-thiol.

Other zero-valent metal particles readily undergo oxidation by thiol, to form thiolates, for example $\mathrm{Pd}$ and $\mathrm{Cu}^{33-36}$ However, Au is clearly a borderline case.

\section{Gold size sensitivity to thiol attack}

Millimeter size pieces of bulk gold do not react with thiols in any refluxing solvent that has been used for digestive ripening, such as toluene, butanone, tert-butyltoluene, or diphenylether. ${ }^{37}$ However, nanoparticle gold does react, but only on the surface. Thus, $\mathrm{Au}_{3800}$ is a stable entity with 365 thiolates where the thiolate is $\mathrm{CH}_{3}\left(\mathrm{CH}_{2}\right)_{10} \mathrm{CH}_{2} \mathrm{~S}^{-38}$

It is proposed herein that the surface energy of a $4-5 \mathrm{~nm}$ particle is high enough to allow an oxidation reaction with thiol, but only a surface reaction. Smaller particles would have a 
higher surface energy and thus could be more fully consumed by the thiol $\longrightarrow$ thiolate + hydrogen process.

Digestive ripening results imply that both smaller and larger nanoparticles are modified until one preferred size is attained, about $5 \mathrm{~nm}$. Smaller particles would be more reactive and under digestive ripening conditions gold atoms or clusters could be "dissolved" by thiols/thiolates and redispersed on larger particles, similar to Ostwald ripening. Larger nanoparticles would be slightly less reactive and perhaps less subject to the thiol $\longrightarrow$ thiolate + hydrogen process, but are subject to thiol-gold atom/cluster solvation and transport, thereby gold atoms or clusters could be transported to other particles. This seems especially likely if crystalline defects in the larger particles are present (scheme 2). Indeed, this type of movement was clearly shown to be possible when thiolated $5 \mathrm{~nm}$ particles of $\mathrm{Au}$ and $5 \mathrm{~nm}$ particles of $\mathrm{Ag}$ were digestively ripened together to form alloy particles of the same size! ${ }^{39-40}$ Thus, a thermodynamic equilibration could be set up and would be sensitive to nanoparticle's size. These data suggest that $5 \mathrm{~nm}$ is a critical size, possessing the optimum surface energy to allow a shell of $\mathrm{Au}-\mathrm{SR}$ to form and thus protect the core of $\mathrm{Au}^{0}$ from further reaction. Of course, this concept is perhaps acceptable for less reactive thiols such as dodecylthiol and not with more reactive thiols. Also, other head groups such as amines have been found to lead to larger digestively ripened particles and clearly other chemical forces are involved. These delicate thermodynamic equilibria can be affected by ligand head group size and reactivity, and metal nanoparticle size.

Next, the category of small clusters is considered. It would appear that a molecular intermediate such as the $\mathrm{Au}(\mathrm{I})-\mathrm{SR}$ unit is involved. More reactive thiols would favor the formation of such species from zero-valent gold clusters. Furthermore, evidence presented above supports the idea of higher reactivity of PET vs alkyl thiols. Now, considering the second step in 
synthesizing small gold clusters, the polymer $\mathrm{Au}(\mathrm{I})-\mathrm{SR}$ (or written formally as $\mathrm{Au}^{+} \mathrm{SR}^{-}$) is exposed to a reducing agent such as $\mathrm{NaBH}_{4}$. Upon encountering this reducing agent $\mathrm{Au}^{+} \mathrm{SR}^{-}$ species would tend to form $\mathrm{Au}^{0} \mathrm{SR}^{-}$, and thus could build its core up to gold clusters. For example, the most well known system is $\mathrm{Au}_{25}(\mathrm{SR})_{18}$, is perhaps better depicted as $7 \mathrm{Au}^{0}$, or $\mathrm{Au}_{7}(\mathrm{Au}-\mathrm{SR})_{18}$.
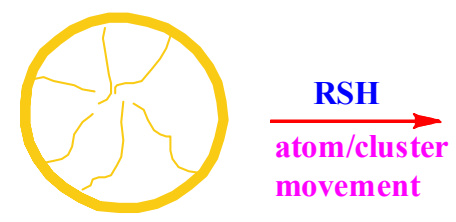

Large particles with crystalline defects

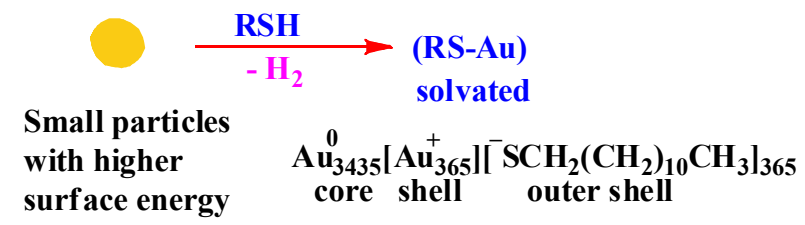

Scheme 2 Illustration of thiol attack on larger, polycrystalline gold nanoparticles. ${ }^{41}$

Therefore, if thiols are reactive enough, and conditions (temperature, solvent) are vigorous enough, even nanogold zero-valent species could be attacked by thiol repeatedly until essentially all gold atoms were oxidized. Then under reducing conditions $\left(\mathrm{NaBH}_{4}\right.$ or other reducing agent) and mild temperature small gold clusters could form and "build up" take place. Along the way, some slightly more stable clusters could be favored, such as $\mathrm{Au}_{25}, \mathrm{Au}_{38}, \mathrm{Au}_{105}$, or $\mathrm{Au}_{225}$, due to electronic structure or closed shells, or other unique features.

Coming back to the larger zero-valent nanoparticles, they would be less reactive than the very small zero-valent clusters. However, under the right conditions, surfaces could be oxidized by thiol. Particle collisions taking place at elevated temperatures of solvent could cause material transfers. $\mathrm{Au}$ atoms/clusters or $\mathrm{Au}^{+} \mathrm{SR}^{-}$partners or clusters must be somewhat mobil, which would be assisted by the presence of excess thiol. In support of this idea, it has been found that 
concentration of nanoparticle gold is important in order to achieve satisfactory digestive ripening results. ${ }^{40}$

Scheme 3 attempts to clarify the possible reaction sequences, and scheme 4 shows balanced equations including side reactions for the three synthetic methods discussed herein.

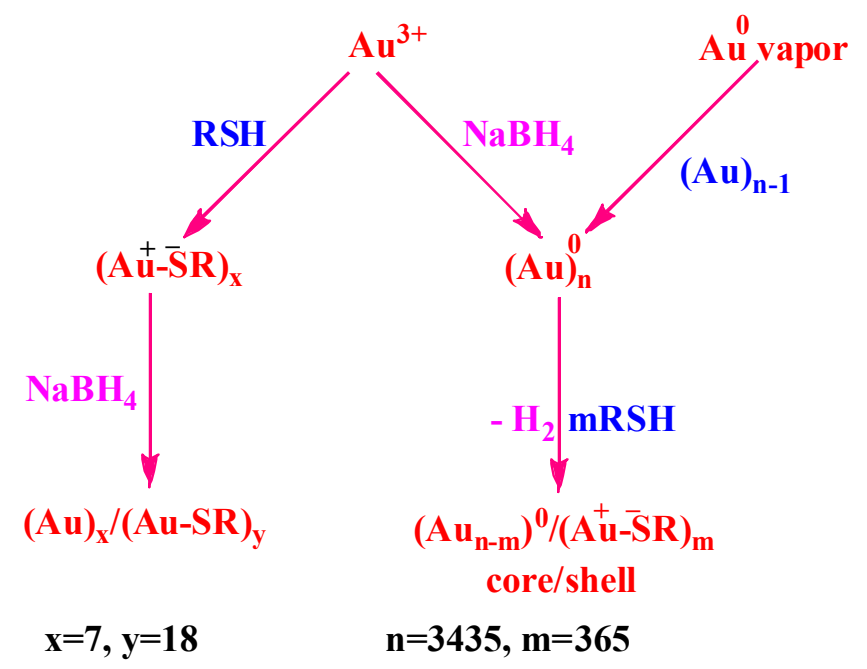

Scheme 3 If gold nanoparticles are formed in one step, followed by thiol treatment larger ( $5 \mathrm{~nm})$ core/shell $\mathrm{Au} / \mathrm{Au}-\mathrm{SR}$ particles can be formed. If Au-SR polymer is formed first, followed by thiol treatment, much smaller molecular $\mathrm{Au} / \mathrm{Au}-\mathrm{SR}$ molecules can be formed. 


\section{Murray et al. synthesis of gold clusters}

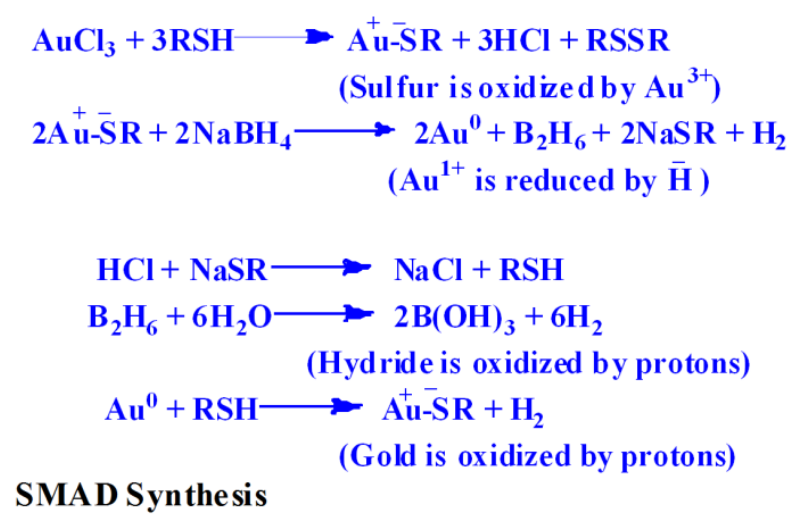

Scheme 4: The likely reactions involved in the Murray, et al. synthesis, ${ }^{15}$ the SMAD synthesis, and the Inverse Micelle synthesis.

\section{Conclusions}

Thiols react with $\mathrm{Au}(\mathrm{III})$ to produce $\mathrm{Au}(\mathrm{I})-\mathrm{SR}$ polymer. Treatment of this thiol polymer with $\mathrm{NaBH}_{4}$ causes reduction of some $\mathrm{Au}(\mathrm{I})$ to $\mathrm{Au}(0)$, but $\mathrm{Au}(\mathrm{I})-\mathrm{SR}$ serves to cap and protect particularly stable very small gold cores. In this reaction scheme, $\mathrm{Au}(\mathrm{III})$ is reduced by thiol to form the $\mathrm{Au}(\mathrm{I})-\mathrm{SR}$ thiolate polymer.

On the other hand, both the SMAD method and Inverse Micelle method leads to Au atoms that rapidly aggregate to form $\mathrm{Au}(0)$ nanoparticles. Thiol reacts with these zero-valent particles to form surface $\mathrm{Au}(\mathrm{I})-\mathrm{SR}$ capping structures. In this reaction scheme, $\mathrm{Au}(0)$ is oxidized by thiol, but only surface gold atoms are attacked. Gold particle size has an influence on extent 
of reactivity with thiols. Certain thiols are more reactive in this way, and PET is more reactive than DDT.

\section{Biographies}

Deepa Jose received her $\mathrm{PhD}$ in materials Science from the Indian Institute of Science, Bangalore, India in 2009. She joined Prof. Klabunde's group at Kansas State University as a postdoctoral research associate in 2011. Her current research work focuses on the digestive ripening and ligand shell modification of thiol capped gold nanoparticles.

John E. Matthiesen is a fourth year undergraduate student at Wartburg College. He worked with Prof. Klabunde for an NSF REU program in 2011 summer. His research was mainly focused on finding out the fate of sulfur bound hydrogen atom during the interaction of gold nanoparticles with thiols.

Christopher Parsons Christopher Parsons is a 3rd year B.S./M.S. student in chemistry at University of Georgia. He worked with Prof Klabunde in 2011 summer for an NSF REU program. Currently he researches in the Marcus D. Lay nanomaterials lab at University of Georgia.

Christopher M. Sorensen is the Cortelyou-Rust University Distinguished Professor at Kansas State University in Physics and Chemistry (Adjunct). He earned BS and $\mathrm{PhD}$ degrees at the Universities of Nebraska and Colorado, respectively. His current research focuses on aggregation phenomena in aerosols and colloids, nanoparticle physical chemistry and light scattering. In 2007 he was named the National Professor of the Year for Doctoral and Research Universities by the CASE/Carnegie Foundation for the Advancement of Teaching.

Kenneth J. Klabunde received a B. A. degree from Augustana College, and Ph.D. from the University of Iowa in 1969. After a postdoc at Pennsylvania State, he worked 9 years at the 
University of North Dakota, and moved to K-state in 1979 as Professor and Department Head. In 1988 he was appointed as University Distinguished Professor. He has had research interests in metal atom chemistry, organometallics, catalysis, and nanotechnology. He is the founder of Nanoscale Corporation, has published numerous papers and written several books in nanoparticles chemistry, and holds over 20 patents. He has won the ACS Midwest Award, University of Iowa alumni award, Popular Mechanics Magazine Breakthrough Invention Award (for a nanopowder that destroys chemical warfare agents).

\section{Acknowledgements}

We are grateful to the Department of Energy (Basic Energy Sciences) for funding. Also, J.E.M. and C.P. thank the National Science Foundation for summer REU support.

\section{References}

(1) Lin, X. M.; Sorensen, C. M.; Klabunde, K. J. Digestive Ripening, Nanophase Segregation and Superlattice Formation in Gold Nanocrystal Colloids. J. Nanopart. Res. 2000, 2, 157-164.

(2) Klabunde, K. J.; Sorensen, C. M.; Stoeva, S. I.; Prasad, B. L. V.; Smetana, A. B.; Lin, X. M. “Digestive Ripening, or 'Nanomachining,' to Achieve Nanocrystal Size Control,” (invited book chapter), Metal Nanoclusters in Catalysis and Materials Science: The Issue of Size Control, Part II Methodologies, ed. Corrain, C. Schmid, G.; Toshima, N. Elsevier Science, Amsterdam, 2008, ch. 11, pgs 233-252.

(3) Prasad, B. L. V.; Sorensen, C. M.; Klabunde, K. J. Gold Nanoparticle Superlattices. Chem. Soc. Rev. 2008, 37, 1871-1883.

(4) Stoeva, S.; Klabunde, K. J.; Sorensen, C. M.; Dragieva, I. Gram-Scale Synthesis of Monodisperse Gold Colloids by the Solvated Metal Atom Dispersion Method and Digestive 
Ripening and Their Organization into Two- and Three-Dimensional Structures. J. Am. Chem. Soc. 2002, 124, 2305-2311.

(5) Lin, X. M.; Jaeger, H. M.; Sorensen, C. M.; Klabunde, K. J. Formation of Long-RangeOrdered Nanocrystal Superlattices on Silicon Nitride Surfaces. J. Phys. Chem. B. 2001, 105, 3353-3357.

(6) Kalidindi, S. B.; Jagirdar, B. R. Highly Monodisperse Colloidal Magnesium Nanoparticles by Room Temperature Digestive Ripening. Inorg. Chem. 2009, 48, 4524-4529.

(7) Barngrover, B. M.; Aikens, C. M. Electron and Hydride Addition to Gold(I) Thiolate Oligomers: Implications for Gold_Thiolate Nanoparticle Growth Mechanisms J. Phys. Chem. Lett. 2011, 2, 990-994.

(8) Qian, H.; Zhu, M.; Andersen, U. N.; Jin, R. Facile, Large-Scale Synthesis of DodecanethiolStabilized $\mathrm{Au}_{38}$ Clusters. J. Phys. Chem. A 2009, 113, 4281-4284.

(9) Wu, Z.; MacDonald, M. A.; Chen, J.; Zhang, P.; Jin, R. Kinetic Control and Thermodynamic Selection in the Synthesis of Atomically Precise Gold Nanoclusters. J. Am. Chem. Soc. 2011, 133, 9670-9673.

(10) Wu, Z.; Chen, J.; Jin, R. One-Pot Synthesis of $\mathrm{Au}_{25}(\mathrm{SG})_{18}$ 2- and 4-nm Gold Nanoparticles and Comparison of Their Size-Dependent Properties. Adv. Funct. Mater. 2011, 21, 177-183.

(11) Qian, H.; Zhu, Y. Jin, R. Size-Focusing Synthesis, Optical and Electrochemical Properties of Monodisperse $\mathrm{Au}_{38}\left(\mathrm{SC}_{2} \mathrm{H}_{4} \mathrm{Ph}\right)_{24}$ Nanoclusters. ACS Nano 2009, 3, 3795-3803.

(12) Qian, H.; Jin, R. Controlling Nanoparticles with Atomic Precision: The Case of $\mathrm{Au}_{144}\left(\mathrm{SCH}_{2} \mathrm{CH}_{2} \mathrm{Ph}\right)_{60}$. Nano Lett. 2009, 9, 4083-4087.

(13) Zhu, M.; Qian, H.; Jin, R. Thiolate-Protected $\mathrm{Au}_{24}\left(\mathrm{SC}_{2} \mathrm{H}_{4} \mathrm{Ph}\right)_{20}$ Nanoclusters: Superatoms or Not? J. Phys. Chem. Lett. 2010, 1, 1003-1007. 
(14) Akola, J.; Walter, M.; Whetten, R. L.; Häkkinen, H.; Grönbeck, H. On the Structure of Thiolate-Protected $\mathrm{Au}_{25}$. J. Am. Chem. Soc. 2008, 130, 3756-3757.

(15) Parker, J. F.; Weaver, J. E. F.; McCallum, F.; Fields-Zinna, C. A.; Murray, R. W. Synthesis of Monodisperse $\left[\mathrm{Au}_{25}(\mathrm{SR})_{18}{ }^{-}\right]\left[\mathrm{Oct}_{4} \mathrm{~N}^{+}\right]$Nanoparticles, with Some Mechanistic Observations. Langmuir 2010, 26, 13650-13654.

(16) Wu, Z.; Suhan, J.; Jin, R. One-Pot Synthesis of Atomically Monodisperse, ThiolFunctionalized $\mathrm{Au}_{25}$ Nanoclusters. J. Mater. Chem. 2009, 19, 622-626.

(17) Zhu, M.; Chan, G.; Qian, H.; Jin, R. Unexpected Reactivity of $\mathrm{Au}_{25}\left(\mathrm{SCH}_{2} \mathrm{CH}_{2} \mathrm{Ph}\right)_{18}$ Nanoclusters with Salts. Nanoscale 2011, 3, 1703-1707.

(18) Parker, J. F.; Kacprzak, K. A.; Lopez-Acevedo, O.; Häkkinen, H.; Murray, R. W. Experimental and Density Functional Theory Analysis of Serial Introductions of ElectronWithdrawing Ligands into the Ligand Shell of a Thiolate-Protected $\mathrm{Au}_{25}$ Nanoparticle. J. Phys. Chem. C 2010, 114, 8276-8281.

(19) Donkers, R. L.; Lee, D.; Murray, R. W. Synthesis and Isolation of the Molecule-like Cluster $\mathrm{Au}_{38}\left(\mathrm{PhCH}_{2} \mathrm{CH}_{2} \mathrm{~S}\right)_{24}$. Langmuir 2004, 20, 1945-1952.

(20) Levi-Kalisman, Y.; Jadzinsky, P. D.; Kalisman, N.; Tsunoyama, H.; Tsukuda, T.; Bushnell, D. A.; Kornberg, R. D. Synthesis and Characterization of $\mathrm{Au}_{102}(p-M B A)_{44}$ Nanoparticles. J. Am. Chem. Soc. 2011, 133, 2976-2982.

(21) Tang, Z.; Robinson, D. A.; Bokossa, N.; Xu, B.; Wang, S.; Wang, G. Mixed Dithiolate Durene-DT and Monothiolate Phenylethanethiolate Protected $\mathrm{Au}_{130}$ Nanoparticles with Discrete Core and Core-Ligand Energy States. J. Am. Chem. Soc. 2011, 133, 16037-16044.

(22) Qian, H.; Jin, R. Ambient Synthesis of $\mathrm{Au}_{144}(\mathrm{SR})_{60}$ Nanoclusters in Methanol. Chem. Mater. 2011, 23, 2209-2217. 
(23) Wolfe, R. L.; Murray, R. W. Analytical Evidence for the Monolayer-Protected Cluster $\mathrm{Au}_{225}\left[\left(\mathrm{~S}\left(\mathrm{CH}_{2}\right) \mathrm{CH}_{3}\right)\right]_{75}$. Anal. Chem. 2006, 78, 1167-1173.

(24) Prasad, B. L. V.; Stoeva, S. I.; Sorensen, C. M.; Klabunde, K. J. Digestive-Ripening Agents for Gold Nanoparticles: Alternatives to Thiols. Chem. Mater. 2003, 15, 935-942.

(25) Prasad, B. L. V.; Stoeva, S. I.; Sorensen, C. M.; Klabunde, K. J. Digestive Ripening of Thiolated Gold Nanoparticles: The Effect of Alkyl Chain Length. Langmuir 2002, 18, 75157520.

(26) Stoeva, S. I.; Prasad, B. L. V.; Uma, S.; Stoimenov, P.; Zaikovski, V.; Sorensen, C. M.; Klabunde, K. J. Face-Centered Cubic and Hexagonal Close-Packed Nanocrystal Superlattices of Gold Nanoparticles Prepared by Different Methods. J. Phys. Chem. B. 2003, 107, 7441-7448.

(27) Stoeva, S. I.; Smetana, A. B.; Sorensen, C. M.; Klabunde, K. J. Gram-Scale Synthesis of Aqueous Gold Colloids Stabilized by Various Ligands. J. Colloid Int. Sci. 2007, 309, 94-98.

(28) Pileni, M. P. Nanocrystal Self-Assemblies: Fabrication and Collective Properties. J.Phys. Chem. B 2001, 105, 3358-3371.

(29) Hasan, M.; Bethell, D.; Brust, M. The Fate of Sulfur-Bound Hydrogen on Formation of Self-Assembled Thiol Monolayerson Gold: ${ }^{1} \mathrm{H}$ NMR Spectroscopic Evidence from Solutions of Gold Clusters. J. Am. Chem. Soc. 2002, 124, 1132-1133.

(30) Petroski, J.; Chou, M.; Creutz, C. The Coordination Chemistry of Gold Surfaces: Formation and Far-Infrared Spectra of Alkanethiolate-Capped Gold Nanoparticles. J. Organomet. Chem. 2009, 694, 1138-1143.

(31) Matthiesen, J. E.; Jose, D.; Soresen, C. M.; Klabunde, K. J. Publication in preparation.

(32) Poirier, G. E.; Pylant, E. D. The self-assembly mechanism of alkane thiols on Au (111). Science 1996, 272, 1145-1148. 
(33) Yang, Z.; Smetana, A. B.; Sorensen, C. M.; Klabunde, K. J. Synthesis and Characterization of a New Tiara Pd(II) Thiolate Complex $-\left[\mathrm{PdSC}_{12} \mathrm{H}_{25}\right]_{6}$ and Its Solution-Phase Thermolysis to Prepare Nearly Monodisperse Palladium Sulfide Nanoparticles. Inorg. Chem. 2007, 46, 24272431.

(34) Yang, Z.; Klabunde, K. J.; Sorensen, C. M. From Monodisperse Sulfurized Palladium Nanoparticles to Tiara Pd(II) Thiolate Clusters: The Influence of Thiol Ligand on the Thermal Treatment of a Pd(II)-Amine System. J. Phys. Chem. C. 2007, 111, 18143-18147.

(35) Ponce, A. A.; Klabunde, K. J. Chemical and Catalytic Activity of Copper Nanoparticles Prepared Via Metal Vapor Synthesis. J. Molec. Catal. A: Chemical 2005, 225, 1-6.

(36) Ponce, A. A.; Smetana, A.; Stoeva, S.; Klabunde, K. J.; Sorensen, C. M. Nanocrystal Superlattices of Copper, Silver and Gold, by Nanomachining. edited by A. Vaseashta, et. al., Nanostructured and Advanced Materials, published in the Netherlands by Springer, 2005, pgs. 309-316.

(37) Parsons, C.; Jose, D.; Sorensen, C. M.; Klabunde, K. J. Publication in preparation

(38) Sorensen, C. M. Nanoparticle Solutions. Chapter 3, pgs. 35-49, in Nanoscale Materials in Chemistry:Environmental Applications,” Erickson, L. E.; Koodali, R. J.; Richards, R. M. editors ACS Symposium Series 1045 (2010).

(39) Smetana, A. B.; Klabunde, K. J.; Sorensen, C. M.; Ponce, A. A.; Mwale, B. Low Temperature Metallic Alloying of Copper and Silver Nanoparticles with Gold Nanoparticles through Digestive Ripening. J. Phys. Chem. B. 2006, 110, 2155-2158.

(40) Smetana, A. Ph.D thesis, 2006 Kansas State University 
(41) Stoeva, S. I.; Zaikovski, V., Prasad, B. L. V.; Stoimenov, P. K.; Sorensen, C. M.; Klabunde, K. J. Reversible Transformations of Gold Nanoparticle Morphology. Langmuir 2005, 21, 102801028. 